\title{
An Evaluation of Information Sources Regarding Drug Use and/or Poisoning Cases of Community Pharmacists in Ankara, Turkey
}

\author{
Ayce Celiker', [PhD] \\ ORCID: 0000-0001-6753-6844 \\ Emre Kara ${ }^{2},[\mathrm{MSc}]$ \\ ORCID: 0000-0002-7034-4787 \\ Sevilay Karahan ${ }^{3},[\mathrm{PhD}]$ \\ ORCID: 0000-0002-8692-7266
}

\begin{abstract}
'Lokman Hekim University Faculty of Pharmacy, Department of Clinical Pharmacy, Ankara, Turkey.

${ }^{2}$ Hacettepe University Faculty of Pharmacy, Department of Clinical Pharmacy, Ankara, Turkey.

${ }^{3}$ Hacettepe University Faculty of Medicine, Department of Biostatistics, Ankara, Turkey.

\section{Corresponding Author: Ayce Celiker}

Hacettepe University Facuty of Pharmacy, Department of Clinical Pharmacy, Ankara, Turkey.

E-mail: aycelike@hacettepe.edu.tr
\end{abstract}

https://doi.org/10.32552/2021.ActaMedica.630

\section{n ABSTRACT Con}

Objective: Exploring and categorizing the drug and/or poisoning information resources available in community pharmacies in Ankara according to some variables, and revealing common opinions regarding the future of the profession and information resources.

Materials and Methods: This study was conducted as an online questionnaire for community pharmacists in Ankara. It had four headings on the pharmacists' demographics, their general information resources, specific resources in specific topics, and 4 suggestions regarding the future of pharmacy and drug information resources.

Results: The number of participants was 134 as $17.9 \%$ of 746 e-mail addresses. Mean ages \pm standart deviation were $40.9 \pm 12.0$ years. The top 3 information sources on poisonings were the internet, colleagues, and physicians with $74.6 \%, 43.3 \%$, and $30.6 \%$, respectively. Participants in the "colleagues" group in terms of poisoning preferences had a shorter period after graduation $(p=0.001)$. In the drug information inquiries package inserts, internet and colleagues were preferred mostly, with $69.4 \%, 63.4 \%$, and $35.8 \%$, respectively. Age groups and graduation years were statistically different regarding the "package inserts" and "colleagues" groups $(p=0.012$ and $p=0.001$, and $p=0.019$ and $p<0.001$, respectively). The most "totally agreed" suggestion was accepting the pharmacies' being important drug and/or poison information resources for consumers with $68.7 \%$.

Conclusion: The pharmacists have been fulfilling their duty of "being an information resource" through rather limited resources. To equip community pharmacists properly, authorities, professional institutions, and universities need to contribute to the process in different ways together with pharmacists being aware of their responsibilities.

Keywords: Drug information, poison information, community pharmacy, internet, package insert

Received: 26 May 2021, Accepted: 22 August 2021,

Published online: 20 November 2021 


\section{INTRODUCTION}

A continuing increase in scientific and technological developments has introduced thousands of drugs and potent dosage forms that have given a wide range of therapeutic choices for prescribers. In the late 1960s and early 1970s, with the advancements in information technology and the invention of modern equipment, the pharmacy profession also gained huge steps besides all other professions. The dramatic change in the philosophy of pharmacy services, gave way for pharmacists to go out of the compounding and dispensing areas closed in pharmacy departments into the wards and clinics of hospitals together with community pharmacy settings. The appearance of pharmacists in clinics facilitated them to take part as team members to prove their competencies and serve as an interface between the clinician and patient with aiming to contribute to rational drug use [1].

Community pharmacies are the easily attainable and cheapest health-related points for people seeking medical advice, and for health care providers asking for information about drugs and poisoning [2]. Nonetheless, fulfilling this responsibility by a given pharmacist is not an easy task, since it necessitates a "management skill". The main aim of this service is not to know the answers for all queries, but to provide qualified, unbiased, reliable, and current information using a comprehensible language through the most proper resources [3]. Pharmacists, especially in developing countries, to overcome this struggle, should adapt their capacities to contemporary and evolving roles. In Turkey, pharmacists have achieved their professions traditionally in hospitals and community pharmacies as small-scale manufacturers of simple formulations in their limited laboratories and dispensers of drug products for many years. Upon regulations of pharmacies and pharmacists' tasks in 1999, providing clinically useful drug information (DI) in both community and hospital pharmacies has been burdened as one of the obligations of pharmacists [4].

The objectives of this study are, firstly to explore and categorize the drug and/or poison information resources available, including usage frequencies of the community pharmacists in Ankara according to some variables. Secondly, to reveal, if any, the common opinions regarding the future of the profession and information resources.

\section{MATERIALS and METHODS}

This study was conducted as a descriptive, online questionnaire, and data was collected between March-April 2015. A self-administered questionnaire was generated by one of the researchers of the study and was pretested and validated by a panel of ten-pharmacist. The completion of the questionnaire was estimated to take 15-20 minutes. Upon finalizing with minor revisions, the questionnaires were distributed by the Ankara Chamber of Pharmacists through a link inserted in e-mails accompanied by a cover letter explaining the purpose of the study. The study population included all community pharmacists on the mailing list of the Ankara Chamber of Pharmacists (The number of community pharmacies in Ankara was 2075 in 2015). However, although there were 1850 e-mail addresses on the mailing list, only 746 (40.3\%) of them were attainable. The pharmacists were asked to complete and return the questionnaires within two weeks. The mailing activity was repeated once more in the same conditions after two weeks following the first e-mail process.

This study was approved by the Hacettepe University Non-Clinical Trials Ethics Committee (GO: 15/144). When the given pharmacist voluntarily accepted filling in the questionnaire at the bottom of the cover letter of the questionnaire, it was accepted that he/she approved to participate in the survey anonymously.

The questionnaire consisted of 23 items in 4 headings of multiple-choice and open-ended questions designed to collect demographic information, general information regarding information resources, specific resources in specific topics, and four suggestions regarding the future of pharmacy and DI resources. Since in some of the queries, there were multiple answers for the participants to choose from; the total percentages were not always $100 \%$. The sources that were questioned in the study were chosen according to the personal experiences of the researchers and published information [5]. In the second heading, respondents were asked to give the names of the books and journals for drug and/or poisoning information available in the pharmacy in an openended question, and to prioritize the mostfrequently used institutions and sources in the handling of DI queries. The topics that were intended as DI queries 
were adverse effects, indications, dosage and route, contraindications, interactions with other drugs/ herbal products/foods, pregnancy and lactation, availability, equivalency with foreign products, stability, intravenous compatibility, and storage conditions.

In DI queries and poisoning cases related sources were listed and in every source, three main examples were asked to be given as open-ended questions. In the third heading, participants were asked to select the frequency of the abovementioned information sources separately related to drug use and poisonings according to the following scale: 1- In every query, 2-In some queries, 3- Rarely, or 4- Never used.

In the fourth heading, a four-suggestion/statement Likert scale was conducted and asked select the proper option, like 1-Completely agreed (four points), 2- Partly agreed (three points), 3- Not fairly agreed (two points), or 4- Never agreed (one point). The suggestions are as follows: A) Community pharmacists are important information resources in answering consumers' drug and/or poisoningrelated queries. B) I believe that I provide proper consultancy in drug-related situations and lead my patients accordingly regarding poisonings in my pharmacy setting. C) No need for any printed material other than internet access in drug-related consultancy and/or poisoning cases in community pharmacies. D) Drug and/or Poison Control Centers (PCCs) will be ranked in the first three worksites of future pharmacy practice.

IBM Statistical Package for the Social Sciences for Windows 21.0 (IBM Corp., Armonk, N.Y., USA) was used for the analysis of data. Percentage, average and standard deviation, median, and minimummaximum were used for the descriptive data. The Chi-square or Fisher Exact tests were used to compare categorical variables and the Student-t, Mann-Whitney $U$ tests were used to compare continuous variables, where appropriate. $p<0.05$ was considered as statistically significant.

\section{RESULTS}

A total of 134 community pharmacists participated in the study. In this study, the response rate to the survey questionnaire was $17.9 \%$ (134 participants from 750 e-mails). The mean years \pm standart deviation (SD) after graduation from faculty was $18.0 \pm 12.2$ years. Almost half of the pharmacists evaluated their computer literacy level as "good" or above. While most of the participants (84.2\%) stated that they knew the English language, 5.3\% of the respondents informed that they knew more than one foreign language. To the question about the language of their mostly applied for the sources in answering the queries regarding drug and/ or poisoning information $62.7 \%$ of participants expressed that they used only Turkish sources (Table 1).

The frequencies of referring to the institutions of community pharmacists were "never"for the Library of the Turkish Pharmacists Association (84.3\%), university libraries (80.6\%), Ankara Chamber of Pharmacists $(78.1 \%)$, and drug manufacturers $(56.7 \%)$. The frequencies of referring to institutions are listed in Table 2.

The most mentioned resource was the "internet" both in poison and drug information inquiries with $74.6 \%$ and $63.4 \%$, respectively. The general distribution of the sources to provide information related to drug use and poisoning cases is given in Table 3.

More than half (55.2\%) of the pharmacists informed that their consumers had asked them for advice in poisoning cases. The top three of the accused agents in those cases were listed as drugs (86.5\%), household products (58.1\%), and caustics and/or corrosives (16.2\%). Respondents stated that the first 3 information sources in poisoning cases were the internet, colleagues, and physicians with $74.6 \%$, $43.3 \%$, and $30.6 \%$, respectively. The ratios of the top 3 resources that referred to "in every query" were the internet with $36.2 \%$, colleagues with $8.4 \%$, and physicians with $3.1 \%$.

When the years after graduation were evaluated separately, the internet was found ranked first in all year groups and reached the highest percentage in the $\geq 26$ years group ( $80.7 \%)$. In the $\leq 15$ years group, "consulting colleagues" was the highest and in the $\geq 26$ years group, the "physicians" choice was higher than the other groups. There was a statistically significant difference in the length of time after graduation in the "consulting to colleagues" group $(p=0.001)$. There was not a statistically significant difference between the groups in the preferred resources regarding academic degrees. The 
Table 1. Demographics of Participants $(n=134), \%$

\begin{tabular}{|c|c|c|}
\hline \multicolumn{2}{|l|}{ Age, mean \pm SD } & $40.9 \pm 12.0$ \\
\hline \multicolumn{2}{|c|}{ Years after graduation from pharmacy school, mean \pm SD } & $18.0 \pm 12.2$ \\
\hline \multirow{2}{*}{ Gender, \% } & Female & 50.0 \\
\hline & Male & 50.0 \\
\hline \multirow{3}{*}{ Academic degree, $\%$} & $\mathrm{BSc} / \mathrm{MP}$ & 87.2 \\
\hline & MSc & 12.0 \\
\hline & $\mathrm{PhD}$ & 0.8 \\
\hline \multirow{5}{*}{ Areas of specialties, $\%$} & None & 82.1 \\
\hline & Pharmacy management & 2.2 \\
\hline & Pharmaceutical toxicology & 2.2 \\
\hline & Clinical pharmacy & 2.2 \\
\hline & Others & 11.3 \\
\hline \multirow{4}{*}{ Computer literacy level, $\%$} & Very good & 18.0 \\
\hline & Good & 38.3 \\
\hline & Intermediate-little & 42.0 \\
\hline & None & 1.7 \\
\hline \multirow{4}{*}{ Foreign language level, \% } & Very good & 6.7 \\
\hline & Good & 21.6 \\
\hline & Intermediate-little & 63.1 \\
\hline & None & 8.6 \\
\hline
\end{tabular}

Table 2. The frequency of the institutions applied in poisonings and drug usage $(n=134),(\%)$

\begin{tabular}{|l|c|c|c|c|}
\hline Institution & Once a week & Monthly & A few times in a year & Never \\
\hline Ankara Chamber of Pharmacists & 1.5 & 2.2 & 16.4 & 78.1 \\
\hline Drug manufacturers & - & 7.5 & 35.1 & 56.7 \\
Turkish Pharmacists Association & 0.7 & 4.5 & 9.7 & 84.3 \\
University libraries & 0.7 & 2.2 & 15.7 & 80.6 \\
\hline
\end{tabular}

Table 3. Information Sources for Poisoning Cases and Drug Usage ( $n=134), n$ (\%)

\begin{tabular}{|l|c|c|}
\hline Source & Poisoning & Drug usage \\
\hline Digital media & $15(11.2)$ & $22(16.4)$ \\
\hline Representatives of drug manufacturers & $\mathrm{N} / \mathrm{A}$ & $24(17.9)$ \\
Physician & $41(30.6)$ & $29(21.6)$ \\
HIZBIB* & $34(25.4)$ & $19(14.2)$ \\
Related books/Journals & $39(29.1)$ & $45(33.6)$ \\
Internet & $100(74.6)$ & $85(63.4)$ \\
Courses/Conferences/Seminars & $6(4.5)$ & $12(9.0)$ \\
Colleague & $58(43.3)$ & $48(35.8)$ \\
Package inserts & $\mathrm{N} / \mathrm{A}$ & $93(69.4)$ \\
\hline UZEM** & $35(26.1)$ & $\mathrm{N} / \mathrm{A}$ \\
\hline
\end{tabular}

*Hacettepe Drug and Poison Information Unit

**National Poison Information Center

N/A: Not assigned

distribution of the preferences of the top 3 sources in queries in poisoning cases according to academic degrees and the distribution of the preference sorting of the top 3 sources in the queries related to poisoning cases according to time after graduation is shown in Table 4.

When the graduation years were evaluated separately according to the choices of drug usage 
Table 4. Preferences in Poisonings According to Years after Graduation from Faculty of Pharmacy and Academic Degrees, n (\%)

\begin{tabular}{|c|c|c|c|c|c|c|c|c|}
\hline \multirow{3}{*}{ Sources } & \multicolumn{8}{|c|}{ Preferences in Poisonings According To... } \\
\hline & \multicolumn{4}{|c|}{ Years after Graduation from Faculty of Pharmacy } & \multicolumn{4}{|c|}{ Academic Degrees } \\
\hline & $\begin{array}{c}\leq 15 \text { years } \\
(n=60)\end{array}$ & $\begin{array}{c}16-25 \text { years } \\
(n=36)\end{array}$ & $\begin{array}{c}\geq 26 \text { years } \\
(n=33)\end{array}$ & p value & $\begin{array}{l}\mathrm{BSc} / \mathrm{MP} \\
(\mathrm{n}=116)\end{array}$ & $\operatorname{MSc}(n=16)$ & $\operatorname{PhD}(n=1)^{*}$ & $\mathrm{p}$ value \\
\hline Internet & $47(78.3)$ & $26(72.2)$ & $25(69.4)$ & 0.684 & $87(75.0)$ & $13(81.3)$ & - & 0.760 \\
\hline Colleague & $35(58.3)$ & $14(38.9)$ & $6(16.7)$ & 0.001 & $45(38.8)$ & $10(62.5)$ & $1(100.0)$ & 0.125 \\
\hline Physician & $19(31.7)$ & $10(27.8)$ & $11(30.6)$ & 0.795 & $33(28.5)$ & $2(12.5)$ & - & 0.235 \\
\hline
\end{tabular}

*This column was not taken into consideration in comparisons

Table 5. Preferences in Drug Usage Enquiries According to Years after Graduation from Faculty of Pharmacy and Academic Degrees, $\mathrm{n}(\%)$

\begin{tabular}{|c|c|c|c|c|c|c|c|c|}
\hline \multirow{3}{*}{ Sources } & \multicolumn{8}{|c|}{ Preferences in Drug Usage Enquiries According To... } \\
\hline & \multicolumn{4}{|c|}{ Years after Graduation from Faculty of Pharmacy } & \multicolumn{4}{|c|}{ Academic Degrees } \\
\hline & $\begin{array}{c}\leq 15 \text { years } \\
(n=60)\end{array}$ & $\begin{array}{c}16-25 \text { years } \\
(n=36)\end{array}$ & $\begin{array}{c}\geq 26 \text { years } \\
(n=33)\end{array}$ & $p$ value & $\begin{array}{l}\text { BSc/MP } \\
(n=116)\end{array}$ & $\operatorname{MSc}(n=16)$ & $\operatorname{PhD}(n=1)^{*}$ & $\mathrm{p}$ value \\
\hline Package inserts & $37(61.7)$ & $22(61.1)$ & $29(87.9)$ & 0.019 & $80(69.0)$ & $12(75.0)$ & $1(100.0)$ & 0.775 \\
\hline Internet & $42(70.0)$ & $21(58.3)$ & $17(51.5)$ & 0.185 & $72(62.1)$ & $13(81.3)$ & - & 0.221 \\
\hline Colleague & $31(51.2)$ & $12(33.3)$ & $2(6.1)$ & $<0.001$ & $39(33.6)$ & $6(37.5)$ & - & 0.980 \\
\hline
\end{tabular}

*This column was not taken into consideration in comparisons

inquiries, it was seen that "package inserts" were preferred mostly in the $\geq 26$ years group (87.9\%), the internet was preferred mostly (70.0\%) and colleagues were consulted mainly $(51.2 \%)$ by the pharmacists who had graduated $\leq 15$ years ago. There was a statistically significant difference in the length of time in the "reading of package inserts" group and "consulting with colleagues" group ( $p=0.019$ and $p<0.001$, respectively). The distribution of the preference ranking of the top 3 sources in the DI queries according to time after graduation is shown in Table 5.

The highest percentage (68.7\%) of "totally agreed" between suggestions was "A-Community pharmacies are important information resources in answering the consumers' drug and/or poisoning related queries". Nonetheless, it was seen that the highest ratio (35.9\%) of "Never agreed" between suggestions was: C-"No need for any printed material except internet access in drug-related consultancy or poisoning cases in community pharmacies". There was a statistically significant difference in the $A$ and $C$ suggestions regarding age groups ( $\leq 45$ vs $>46$ years, $p=0.034$ and $p=0.047$, respectively) (Table 6).

\section{DISCUSSION}

Providing proper and adequate pharmaceutical and toxicological counseling to consumers, together with monitoring and providing care for their health, is one of the most helpful roles of

Table 6. The suggestions about community pharmacies and pharmacists, median (Inter Quartile Range)

\begin{tabular}{|c|c|c|c|c|c|c|}
\hline \multirow{2}{*}{ Suggestions } & \multicolumn{3}{|c|}{ According to age groups } & \multicolumn{3}{|c|}{ According to academic degrees } \\
\hline & Ages $\leq 45$ & Ages $\geq 46$ & p value & $\mathrm{BSc} / \mathrm{MP}$ & MSc & $\mathrm{p}$ value \\
\hline \multirow{2}{*}{ Suggestion A } & 4 & 4 & 0.034 & 4 & 4 & 0.574 \\
\hline & $(3,8-4,0)$ & $(3,0-4,0)$ & & $(3,0-4,0)$ & $(3,0-4,0)$ & \\
\hline \multirow{2}{*}{ Suggestion B } & 3 & 3 & 0.553 & 3 & 3 & 0.688 \\
\hline & $(3,0-4,0)$ & $(3,0-4,0)$ & & $(3,0-4,0)$ & $(3,0-4,0)$ & \\
\hline \multirow{2}{*}{ Suggestion C } & 2 & 2 & 0.047 & 2 & 2 & 0.407 \\
\hline & $(1,0-2,0)$ & $(1,0-3,0)$ & & $(1,0-3,0)$ & $(1,0-2,0)$ & \\
\hline \multirow{2}{*}{ Suggestion D } & 3 & 3 & 0.900 & 3 & 3 & 0.930 \\
\hline & $(3,0-4,0)$ & $(3,0-4,0)$ & & $(3,0-4,0)$ & $(3,0-4,0)$ & \\
\hline
\end{tabular}


community pharmacists [6]. It was shown that the provision of acceptable DI to consumers being in an ideal position leads to increase luminary of a given community pharmacy besides enhancing satisfaction through medication management of consumers [7]. In the studies from various countries, it was noted that generally similar types of drug-related inquiries of consumers were referred to community pharmacists, such as adverse effects, drug and food interactions, other treatment choices including nonmedicinal ones, indications, and basic instructions and duration of treatment $[8,9]$. Therefore, the key point for a community pharmacist to be a trustworthy, upto-date, and user-friendly "information source" for people. Providing efficient information through the most qualified resources for inquiries can reduce the possibility of medication errors, and contribute to rational drug use [10].

Internet was the most consulted information source for poison. The following sources were colleagues and physicians with $43.3 \%$ and $30.6 \%$, respectively. There were not any statistically significant differences regarding gender, compatible with Wazaify's study [11]. When the choices of references were evaluated in another study according to genders, it was found that females were dominant in retrieving $\mathrm{DI}$ from textbooks, the internet, and $\mathrm{DI}$ centers [12]. However, the smaller sample size than this study, and male dominance in the number of respondents in the most of other studies, may have affected those results.

Although the preferences according to age groups as an intragroup were not changed regarding poisoning inquiries, the $\geq 56$ years group was the most prominent with $89.5 \%$ in favor of the internet. Since there was not a statistically significant difference between the groups, this result deserves to be viewed more closely. The reason for this surprising datum could be grounded from two causes. Firstly, since the size of the sample was small, namely 31 participants, the results did not represent the whole population; and secondly, since more reliable and updated sources in the pharmacy setting were not available, those participants may have considered an easier and more private method of referring to the internet than other choices. When the age groups were compared according to the options, the results were as anticipated, namely, the $\leq 35$ years group ranked first in internet usage as being the most computer literate group as well.

When the preferences regarding the sources in drug-related queries were distributed according to age groups as an intragroup it was found that package inserts were referred mostly by the youngest and oldest participants, while the internet was preferred by ages from 36 to 55 years. The list of the age groups according to options showed that statistically significant differences in terms of the "package inserts" and "consulting with colleagues" groups, namely "package inserts" were scored mostly by ages $\geq 56$ and "consulting with colleagues" were selected by ages $\leq 35$ years. In Udezi's and Wazaify's studies, which were the only ones compared for the age groups, age did not have any influence on the choice of references [11, 13].

The analysis of the top three choices in answering the poison queries according to academic degrees did not have a statistically significant difference between the respondents who had no academic degree other than an MP/BSC and the pharmacists who had MSc degree, both choosing the internet as a source. Nevertheless, since the majority (86.6\%) of the participants were composed of pharmacists with an MP/BSc degree in this study, the situation could be considered as a limitation in terms of evaluating this item accurately. On the other hand, academic degrees did not have any impact on the choice of the source in DI inquiries, namely both the MP/BSC and MSc groups ranked package inserts first, and internet and colleagues followed it. Any information regarding if there was any influence of academic degrees on the choice of references was not available in the literature review. Nonetheless, the BSc ratios in other studies were reported as $44.0 \%$ [14], 56.6\% [12], and 97.3\% [15]. In Gelayee's study, the percentage of pharmacists with an MSc degree was reported as $2.1 \%$ [12]. The discrepancies with other studies were considered as the results of the selection criteria of participants and the legislation of pharmacy schools regarding graduation.

Package inserts were preferred mostly in the $\geq 26$ years group $(87.9 \%)$, the internet was preferred mostly $(70.0 \%)$ and colleagues were consulted mainly (51.2\%) by the pharmacists who graduated $\leq 15$ years ago, and these consequences were statistically significant about the length of time 
$(p=0.019)$. Similar to this survey, in Gelayee's study, experienced participants preferred drug package inserts more than the less experienced ones. Other dominant choices in the same group were reported as national treatment guidelines [12]. Al Tabakha showed that DI sources as a course or as a topic were not among the references of older graduates [16].

One of the interesting results of the present study is that although the majority of the participants (84.2\%) indicated that they knew English, they stated that almost $63 \%$ of them preferred to refer to sources solely in Turkish in answering inquiries. This implied that the sources in their native language were the primary resource. However, if the information sought had not been found or was inadequate in those sources, the respondents did not report whether they went to English sources as the second step or finished searching. Knowing a foreign language provides a great contribution in fulfilling this function in countries like Turkey if the official language is other than English, or other global languages. It seemed that the language barrier might have hardened to attain the relevant information as quickly as needed. In some other studies also, this problem was emphasized $[17,18]$.

In the present study, $56.3 \%$ of the participants indicated their computer literacy level as "good" and "very good". In studying the relationship between computer literacy level and the time after graduation, it was found that the ratio of higher levels of computer literacy decreased in the $>21$ years after graduation group $(p=0.005)$. This could be the consequence of the tendency of educationrelated computer use through formal education or private efforts of the younger generations.

When the institution referrals in answering the inquiries were listed, only the pharmaceutical manufacturers and representatives become prominent (56.7\%) as "mostly preferred to consult" as compared to other institutions including pharmaceutical societies and university libraries. This finding was supported by the comparisons of the most referred DI resources section. From this result, it could be inferred that the representatives who make contact frequently with the pharmacist, could bridge between the pharmacy and the company easily. Therefore, the pharmacists could have saved time without additional effort in attaining relevant information. The logic of this choice is explained as if those reliable and independent resources were unavailable, outdated, or unreachable for a given pharmacist, he/she was obliged to take advice from representatives of pharmaceutical companies or colleagues by Zehnder [14]. Nonetheless, the reliability, accuracy, currency, and objectivity can be highly questionable under these circumstances regarding information obtained through commercial sources despite the presumption that the commercial information can be more current than that of outdated printed materials [19]. There are some related results in the literature exceeding the percentage that was obtained in the present study or dropping back [11, 19-21]. Other institutions referred were addressed in only Hennigen's study [22], where $52.3 \%$ of the pharmacists accessed the homepages of professional bodies. In the present study, on the other hand, the percentages of consulting "at least a few times a year" of the Turkish Pharmaceutical Association, Ankara Chamber of Pharmacists, or university libraries were $14.9 \%, 20.1 \%$, and $18.6 \%$, respectively.

One of the most referred $3 \mathrm{DI}$ resources were package inserts with a high preference $(69.4 \%)$ in this report. In general, package inserts were used "in every query" almost by half of the participants. In other studies, only Diobi's study exceeded this rate with $98.4 \%$, while in Gelayee's and Al Tabakha's studies disagreeing with $39 \%$ and $13.9 \%$, respectively $[12,16,23]$. Although those sources are always available in the pharmacy setting, the currency, appropriateness, and responsiveness are controversial since some changes might have been realized during the elapsed time from releasing to the market and the given time to reach the pharmacy [24]. Therefore, there is a risk that the pharmacist might have misdirected the consumer. Instead, the recent online websites containing the information in the package inserts in Turkish can fill in the deficiency of the printed forms by including the most recent approved information. On the other hand, as a compilation of FDA-approved package inserts Physicians' Desk Reference ${ }^{\circledR}$, can also be accepted in this class. The reference ratio in this study was $0.7 \%$. The preferences were in decreasing percentages from 44.2 to 2.0 in other studies $[5,11,25-28]$.

Although the internet is accepted as a comprehensive source where one can rapidly 
attain the latest health information, which enables it to contribute to ameliorating healthcare, it is under the user's responsibility to search critically and scientifically and make the best choice through an abundance of websites. Seeking and evaluating a scientific issue through websites needs prior knowledge and training about the techniques and related professional websites according to accepted criteria and quality labels such as the Health on the Net Foundation Code of Conduct (HONcode ) [24] or the Utilization Review Accreditation Commission (URAC) [26]. Without any pre-education about website usage at least double-checking the information obtained through various websites should be recommended and some addresses should be publicized by the professional societies or local authorities that would be of help for community pharmacists in answering poisoning or drug-related queries they encountered.

In DI queries $35.8 \%$ and in poisoning queries $43.3 \%$ of respondents specified "colleagues" as one of the top three references in the present study. This finding suggested that there were more information sources attainable in Dl inquiries despite poisoning cases. Therefore, consulting colleagues were more feasible for the pharmacists who did not have specific sources in poisoning cases. In other studies, higher percentages were encountered from $94 \%$ to $37 \%[12,21,25,28]$. The rank of "colleagues" between all references was found as $1.29 \pm 0.77$ in Udezi's study [13].

As one of the other drug or poison information resources, DI centers or PCCs in the present study were underutilized. The ratios for two different PCCS (UZEM and HIZBIB) were almost $1 / 4$ of the participants, while for DI center (HIZBIB) was only used by $14.2 \%$. The usage of institutions in this survey supported this outcome, namely UZEM and HIZBIB were "never" consulted by more than half of the respondents. This worrisome result could be attributed to inadequate publicity of those specific resources. Gelayee et al. reported that DI centers were"never" consulted by $70.8 \%$ of the respondents [12]. Some of the results of foreign studies were compatible with outcomes for DI centers from $14,8 \%$ to $29.2 \%[12,23]$ however higher preferences were also pronounced by Hennigen and Chan [22, 25]. In Rae's study, DI centers were in the 6th rank [5]. The popularity of PCCs was less than DI centers in another study [22]. The authors drew attention to develop and activate them through promotions $[5,25]$.

A Likert scale was performed in a 4-item suggestion list, to see whether the participants agree or not. The highest positive ratio (68\%) was regarding accepting community pharmacies as information resources for consumers (Suggestion A). The most (36\%) "Never agreed" suggestion, on the other hand, was regarding needing no source but the internet at the community pharmacy setting (Suggestion C); while the "totally agreed" answer was almost 7\% for this suggestion. Nevertheless in Zehnder's study, the percentage for a suggestion almost reminiscent of ("A-The focus of community pharmacy transforms more and more from products to patients as it is becoming an information center") was only $4 \%$ [17]. More than $1 / 3$ of respondents of the present study "totally agreed" with suggestion C ("I believe that I provide proper consultancy in drugrelated situations and lead accordingly my patients in poisonings in my pharmacy setting"). Those participants might have been apt in using drug or poisoning information resources more efficiently. On the other hand, since this survey was conducted through self-administered questionnaires, working conditions could not be observed.

When a comparison was performed between age groups and the suggestions, significant differences were found. For suggestion $A$, the younger group agreed more than the older respondents. This was considered that older participants were more accustomed to working in an old way. However, for suggestion $C$ older pharmacists agreed more than the younger ones. This might have been derived from a concern about the future. The comparison of $A$ and $C$ suggestions with academic degrees and computer literacy levels did not show any statistically significant difference between the groups. Any other study related to these suggestions was not encountered.

There are several noteworthy limitations in this study. Firstly the population was rather small, so the outcomes cannot be generalized and the respondents cannot be considered as the representatives of all community pharmacists. Ankara is the capital city of Turkey, so a larger scaled survey including the pharmacies in less facilitated regions is under consideration at the moment. Some answers could be exaggerated by the respondents because of social desirability 
bias. In the questionnaire the general manner was investigated, so recalling the problem of the participants could have influenced the results. Internet use as a drug or poison information reference by the respondents might have been overestimated due to the electronic form of the survey because the participants would already be more technologically well informed.

In conclusion, although electronic sources have been used by most of the participants, relevant websites being distinguished from the "information garbage" using scientific criteria seems questionable. Although it is a valuable opportunity to have internet connections throughout the community pharmacy settings in Ankara, the knowledge on how to use it scientifically seems to be the main difficulty at the moment. To equip community pharmacists in the best manner, regularly updated national hard copy and online references containing accurate, unbiased, and reliable drug and poisoning information along with organizing continuing education courses must be implemented by official authorities, including ministries and related bodies, professional institutions and universities. Additionally, drug information centers or PCCs should promote their activities through professional meetings, individual services, and training during formal education.

\section{CONFLICT Of INTEREST STATEMENT}

Authors declare no conflicts of interest.

\section{ne) REFERENCES Ceen}

[1] Carter BL. Evolution of Clinical Pharmacy in the USA and Future Directions for Patient Care. Drugs Aging. 2016 Mar;33(3):169-77.

[2] Kostagiolas PA, Bairaktaris KD, Niakas D. An information behaviour investigation of the community pharmacists in Greece for developing library and information services. Health Info Libr J. 2010 Mar;27(1):46-56.

[3] Iwanowicz SL, Marciniak MW, Zeolla MM. Obtaining and providing health information in the community pharmacy setting. Am J Pharm Educ. 2006 Jun 15;70(3):57.

[4] Resmi Gazete: 6308 sayılı Eczacılar Ve Eczaneler Hakkında Kanun İle Uyuşturucu Maddelerin Murakabesi Hakkında Kanunda Değişiklik Yapılmasına Dair Kanun. 2012; Sept 2020 http://www.resmigazete.gov.tr/ eskiler/2012/05/20120531-3.htm

[5] Rae CE, Rappaport HM, Mahajan P. Drug information sources used by community pharmacists in Louisiana: a preliminary study. J Pharm Technol. 1992 Jan-Feb;8(1):30-3.

[6] Ghaibi S, Ipema H, Gabay M; American Society of Health System Pharmacists. ASHP guidelines on the pharmacist's role in providing drug information. Am J Health Syst Pharm. 2015 Apr 1;72(7):573-7.

[7] Whitehead P, Atkin P, Krass I, et al. Patient drug information and consumer choice of pharmacy. International Journal of Pharmacy Practice. 1999 7(2): 71-79.

[8] Nair K, Dolovich L, Cassels A, et al. What patients want to know about their medications. Focus group study of patient and clinician perspectives. Can Fam Physician. 2002 Jan;48:104-10.

[9] Burghle A, Abrahamsen B, Lundby C, et al. Customers' information seeking behavior prior to community pharmacy visits: A community pharmacy survey. Res Social Adm Pharm. 2020 Oct;16(10):1442-1446.
[10] Jeetu G, Girish T. Prescription drug labeling medication errors: a big deal for pharmacists. J Young Pharm. 2010 Jan;2(1):107-11.

[11] Wazaify $M$, Maani M, Ball D. Drug information resources at community pharmacies in Amman, Jordan. Int J Pharm Pract. 2009 Jun;17(3):151-5.

[12] Asmelashe Gelayee D, Binega Mekonnen G, Birarra MK. The Needs and Resources of Drug Information at Community Pharmacies in Gondar Town, Northwest Ethiopia. Biomed Res Int. 2017;2017:8310636.

[13] Udezi WA, Oparah AC, Enyi KU. An Investigation of Drug Information Needs of Nigerian Pharmacists. Drug Information Journal. 2007;41(4):471-479.

[14] Yusuf H, Abdu-Aguye SN, Suleiman HO, et al. Utilization of electronic drug information resources by pharmacists practicing in hospital and community settings in Maiduguri, Nigeria. Journal of Pharmaceutical and Allied Sciences 2019;16:3138-3145.

[15] Khan TM, Emeka P, Khan AH. Drug Information Activity and Nonprescription Requests Over the Malaysian Counter. Ther Innov Regul Sci. 2013 Mar;47(2):198-202.

[16] Al-Tabakha MM, Akoulah LH, Fahelelbom KM. Drug information in community pharmacy and outpatient pharmacy in Al Ain City, U.A.E.: A descriptive study. Int J Pharm 2013; 3: 316-322.

[17] Zehnder S, Beutler M, Bruppacher R, Ehrenhöfer T, Hersberger KE. Needs and use of drug information sources in community pharmacies: a questionnaire based survey in German-speaking Switzerland. Pharm World Sci. 2004 Aug;26(4):197-202.

[18] Jaradat N, Sweileh W. Drug information for community pharmacies: Survey on needs and use of drug information with special focus on new information technology. AnNajah Univ J. Res (N. Sc) 2003; 17:287-300. 
[19] Ziegler MG, Lew P, Singer BC. The accuracy of drug information from pharmaceutical sales representatives. JAMA. 1995 Apr 26;273(16):1296-8.

[20] Hassali MA, Khan TM, Shafie AA. Use of drug information resources by the community pharmacist in Penang, Malaysia. Inform Prim Care. 2010;18(3):213-6.

[21] Al-Farsi SF, Al Rahbi HAM, Chitme HR. Informatıon resources avarlable at community pharmacies in Oman. Int J Pharm Sci Res 2014;5:2320-2329.

[22] Hennigen FW, Fischer Ml, Camargo AL, et al. Diagnosis of the availability and use of drug information sources in drugstores and pharmacies in southern Brazil. Brazilian Journal of Pharmaceutical Sciences 2009;45:287-294.

[23] Diobi K, Fakeye TO, Adisa R. Community pharmacists' perception of the relevance of drug package insert as source of drug information in Southwestern Nigeria. TJPR 2013;12:439-443.
[24] Boyer C. When the quality of health information matters: Health on the Net is the Quality Standard for Information You can Trust 2013. Access date: Oct 9, 2020. Available at: https://www.hon.ch/Global/pdf/TrustworthyOct2006.pdf.

[25] Chan TY, Lee KK, Critchley JA. The needs and sources of drug information among pharmacists in Hong Kong. J Clin Pharm Ther. 1996 Oct;21(5):325-30.

[26] Wong PS, Ko Y, Sklar GE. Identification and evaluation of pharmacists' commonly used drug information sources. Ann Pharmacother. 2009 Feb;43(2):347-52.

[27] Schrimsher RH, Freeman MK, and Kendrach M. A Survey of Drug Information Resources in Alabama Pharmacy Facilities. Drug Information Journal 2006;40(1):51-60.

[28] Moorman KL, Macdonald EA, Trovato A, Tak CR. Assessment and use of drug information references in Utah pharmacies. Pharm Pract (Granada). 2017 Jan-Mar;15(1):839. 